\title{
Školovanje konjskilh vidara, kuršmida i veterinara na Veterinarskom fakultetu u Beču i drugiim gradovima u današnjoj Austriji
}

\author{
P. Džaja*, S. Sinković, M. Palić, J. Mihalj i K. Severin
}

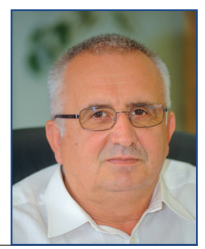

\section{Sažetak}

U radu je prikazan razvoj veterinarskog školstva s posebnim osvrtom na današnji Veterinarski fakultet $\mathrm{u}$ Beču, jer je nekada većina naših veterinara najčešće završavala fakultete $u$ Beču, Budimpešti, Pragu, Lavovu i Italiji. Studij raznih oblika veterinarstva u liječnika i kirurga odvijao se na 4 načina u obliku: kraćih tečajeva iz veterinarstva, redovitog studija "veterinarstvo," poslijediplomskog studija odabranih liječnika i kirurga te posebnog oblika poslijediplomskog studija za medicinare i kirurge. U Bečkom veterinarskom zavodu bile su sljedeće kategorije učenika: obični kovači, poljodjelci, pastiri, lovci i ovčari, časnici, budući okružni liječnici i okružni ranarnici, slušači za pregled mesa i stoke, kuršmidi i pravi veterinari. Burnu povijest razvitka i preobrazbi Veterinarskog fakulteta u Beču prikazana je kroz nekoliko faza do današnjeg dana i to od: 1766.-1777. g., 1777.1795. g., 1795.-1808. g., 1808.-1812. g., 1812. 1850. g., 1850.-1896. g., 1897.-1905. g., 1905.1919. g. i od 1912.-1976. g. do danas.

Ključne riječi: školovanje, konjski vidari, kuršmidi, veterinari

\section{Uvod}

Poznato je da je 3000 god. prije Krista u Egiptu postojala posebna viša škola „Dom života“ u kojoj se uz druge znanstvene discipline učilo i veterinarstvo. Povijest veterinarstva nas podsjeća da se je u salernskoj školi (1100. g. do 1811. g.) koja je preteča medicinskih fakulteta radila razudba životinja, a predavala se „,anatomija životinja i bolesti stoke“. U Italiji je najstarija katedra za veterinarstvo od 1600. g. pod nazivom „Lektorat za veterinarstvo.“ U Njemačkoj najstariju katedru veterinarstva ima Rin-

teln 1730. g., Gotingen 1737. g., Munster 1779. g., Freiburg 1783. g., Giessen 1785. g., Wurzburg 1791. g. i München 1800. g. U Münchenu je donesena naredba da svi liječnici koji žele biti sudski liječnici moraju imati položeno veterinarstvo. Sveučilišta i medicinski fakulteti gdje su osnovane katedre za veterinarstvo su u: Beču 1775. g., Grazu 1777. g., Innsbrucku 1781. g., Pragu 1784. g., Lavovu 1784. g., Budimpešti 1786. g., Padovi 1773. g., Paviji 1817. g., Freiburgu 1774. g. te Milanu i Klarvari 1790. g.

Dr. sc. Petar DŽAJA*, dr. med. vet., redoviti profesor, (dopisni autor, e-mail: dzaja@vef.hr), Veterinarski fakultet Sveučilišta u Zagrebu, Hrvatska; Sonja SINKOVIĆ, dr. med. vet., Hrvatski veterinarski institut Zagreb, Hrvatska; Magdalena PALIĆ, dr. med. vet., Veterinarski fakultet Sveučilišta u Zagrebu, Hrvatska; Josip MIHALJ, dr. med. vet., Veterinarska ambulanta Soljani, Hrvatska; dr. sc. Krešimir SEVERIN, dr. med. vet., redoviti profesor, Veterinarski fakultet Sveučilišta u Zagrebu, Hrvatska 
Izvan austro-ugarske monarhije osnovane su katedre u Harkovu 1805. g., Vilniusu 1849. g., Varšavi 1849. g., Moskvi i Kazanu 1815. g. i Petrogradu 1808. g. ${ }^{1}$

Među veterinarskim školama $u$ Europi koje su djelovale na području veterine mogu se nabrojiti: ${ }^{2}$

Medicinski fakultet u Salernu 1215.1250. g., s Odjelom lijekova za životinje.

Sveučilište Rintheln 1612.-1810. g. s naukom o epidemijama u životinja.

Carska konjušnica u Beču s boljom skrbi za konje, car Karlo VI. (prije 1740. g.)

Veterinarsko medicinska škola u Beču, 24. 3. 1765. g.

Ecole vétérinaire u Lyonu, 1762. g., za bolju skrb konja.

Carsko kraljevska škola za liječenje konja i operacije, 1765. g. u Beču.

Ecole vétérinaire u Alfortu, 1766. g.

Veterinarska škola u Torinu, 1769. g.

Škole o lijekovima za životinje u Kopenhagenu, Uppsali i Hanoveru, 1773.-1778. g. ${ }^{3}$

Najstarija katedra u Europi pod nazivom "Lektorat za veterinarstvo" osnovana je 1600. g. na sveučilištu u Perugi, a u Njemačkoj je Sveučilište u Rinthelmu 1730. g. prvo uvelo katedru za veterinarstvo. U salernskoj školi je predavana komparativna anatomija domaćih životinja i liječenje stoke. Na Medicinskom fakultetu u Paviji predmet komparativna anatomija domaćih životinja i liječenje stoke je predavao Slovenac prof. Laurin 1817. g. koji će kasnije postati direktor Veterinarske škole u Milanu koja je potpala pod fakultet $\mathrm{u}$ Paviji. U Padovi isti je predmet predavao prof. Orus koji je 1775. g. boravio u Dalmaciji. ${ }^{4}$

1 Orban, R. (1995.): Katedre za veterinarstvo na medicinskim fakultetima i sveučilištima podunavskih zemljama u posljednja tri stoljeća. Vet. stn. 26, 35-38.

2 Adamczyk, E. (1998.): Ranarno veterinarskomedicinsko obrazovanje u Europi. Vet. stn. 29, 161-167.

3 Adamczyk, E. (1998.): Ranarno veterinarsko-medicinsko obrazovanje u Europi. Vet. stn. 29, 161-167.

4 Orban, R. (1977.): Studij veterinara kod liječnika i kirurga od 18. do 20. stoljeća.
Proa veterinarska škola na svijetu utemeljena je u Lyonu godine 1761. g., a počela je s radom 1762. g. Austrija osniva prvu Veterinarsku školu 1768. g. u Beču, Italija 1769. g., u Torinu, Njemačka 1771. g. u Göttingenu i 1778.g. u Hannoveru, 1790. g. u Berlinu., Danska 1773. g. u Kopenhagenu, Švedska 1775. g. u Skari, Mađarska 1786.g. u Budimpešti, Engleska 1791. g. u Londonu te Španjolska 1792. g. u Madridu. Nastava je najprije trajala dvije godine, a među nastavnim predmetima predavala se i gramatika. U početku je glavni nastavni objekt bio konj, dok je govedo kao pacijent registrirano tek 1785. god. Giessenska Veterinarska škola je prva, 1830. god. postavila kao uvjet za upis svojih kandidata završenu gimnaziju, a prva je počela i svojim diplomantima dijeliti doktorat veterinarske medicine. U Habsburškoj Monarhiji dekretom je utemeljena vojna veterinarska škola $u$ Вeču, 1765. g., a od 1767. g. u školu su se mogli upisivati i civili.

Od srednjih medicinskih škola veterinarstvo se slušalo u Celovcu 1776. g., Trstu 1778. g., Innsbrucku 1818. g., Grazu 1776. g., Bambergu 1789. g., Ljubljani 1795. g., Olomoucu 1813. g. te Salzburg, Linzu i Klausenbergu. U to je vrijeme djelovalo 10 fakulteta i srednjih medicinskih škola.

Osim izobrazbe studenata medicine i učenika kirurgije organiziraju se duži ili kraći tečajevi iz veterinarskog umijeća, a koji su željeli dobiti znanje veterinara i veterinarskog pomoćnika (Kuršmida) ili potkivača. Ovi tečajevi organiziraju se i puno prije nego li su uvedeni navedeni predmeti pa je tako od 1770. g. do 1790. g. stotine liječnika i kirurga-ranarnika prisustvovalo ovim tečajevima s ciljem da dobije dopusnicu rada u državnoj službi. Na Medicinskom fakultetu u Beču ispiti iz veterinarstva su uvedeni iza 1910. g., a znaju se ispitivači sve do 1928. g. ${ }^{5}$

Znanstveno društvo za povijest zdravstvene kulture, Zagreb.

5 Orban, R. (1976.): Razvoj izobrazbe veterinara na veterinarskoj školi u Beču od 1765. do danas. 
Pokušaji za održavanje nastave iz veterinarstva na Medicinskom fakultetu u Beču poznati su od 1765. g. kada je van Sweiten postao protomedik u Beču i kada poziva dr. Žagara (biofizik u Moravskoj) da preuzme navedena predavanja a koji je u Monarhiji bio poznat kao pisac veterinarskih djela. Žagar to odbija navodeći da ne zna dobro njemački književni jezik. Iz ovoga se da zaključiti da su ta predavanja bila namijenjena kirurzima, ali ne i liječnicima koji su predavanja slušali na latinskom jeziku. Sljedeće godine osnovana je na Medicinskom fakultetu posebna komisija koja je trebala organizirati popularna predavanja iz veterinarstva iz čega bi se moglo zaključiti da su ta predavanja bila za kirurge koji su najčešće suzbijali zarazne bolesti na terenu, a prije 10-tak godina donesen je propis da i kirurzi moraju pohađati fakultetsku nastavu iz teorije medicine.

Prvi oblik studija bili su tečajevi iz veterinarstva koji su se počeli održavati u Beču 1775. g. na Medicinskom fakultetu, a prvim profesorom predmeta komparativna anatomija domaćih životinja i liječenje stoke imenovan je dr. Paul Adami. Od 1777. g. školu preuzima dr. Wolstein (koji će od 1781.-1794. g. biti imenovan profesorom i predavačem tečajeva za liječnike i kirurge, jer je prije napisao knjigu po kojoj se učilo veterinarstvo), a nazivala se Veterinarski institut. Dr. Adami je ostao na Medicinskom fakultetu predavati veterinarstvo (ukaz carice). Od 1795. g. tečajeve u Beču održava dr. Knobloch koji je bio profesor veterinarstva u Pragu. Iza njega tečajeve održava dr. Pessina. O slušanju tog predmeta izdavala se (na medicini) posebna svjedodžba svakom liječniku i kirurgu koji je želio dobiti posao u državnoj službi, tzv. fizikat da je odslušao i položio veterinarstvo.

Drugi oblik studija veterinarstva bilo je uvođenje obveznog predmeta veterinarstvo $u$ redoviti studij na medicini i na školama za kirurge. Tako je 1785. g. veterinarstvo bilo uvedeno u Medicinsko-kiruršku akademiju u Beču. Ovaj predmet studenti medicine i kirurzi slušali su u 5 ., a đaci kirurške škole najprije u 3., a kasnije 1823. g. u 7. semestru. Prva tri nastavnika koji su bili predavači tečajeva: dr. Wolstein, Knobloch i Pessina pa prof. Vietz koji je od 1812. g. postao direktorom Veterinarske škole i koji je posjetio cijelu jadransku obalu organizirajući karantensku službu te je 1815. g. sastavio i poslao caru novi zakon o karantenama na Jadranu iz Zadra (preminuo je u Zadru 1815. g. od tifusa). Kasnije veterinarstvo predaje prof. Hayne, do 1855. g. predaje Slovenac, dr. Simon Strupi, honorarno i besplatno, a od 1895.-1910. srijemski Srbin prof. dr. Čokor. Ovaj predmet se na medicini predavao od 1785. do 1910. g. ili 145 godina.

Od 1807. g. Vojna krajina namješta službeno graduirane veterinare kada šalje 19 vojnih liječnika na Bečku veterinarsku školu, gdje su završili za liječnike propisan dvogodišnji tečaj i postigli čin i naziv veterinar. Tako su 1809. godine 18 pukovnija i jedan šajkaški bataljon dobili po jednog veterinara koji je boravio u sjedištu pukovnije i dobivao 200 forinti plaću, a kojemu je bio zadatak osim liječenja ljudi i besplatno liječenje i suzbijanje stočnih zaraza o čemu je morao slati godišnje izvješće u Beč o stanju stočarstva i veterinarstva, o suzbijanju zaraza i liječenju stoke.

Od 3. 11. 1810. g. donosi se Dekret br. 16085 kojim se naređuje da se $u$ habzburškim zemljama postave veterinari što vjerojatno nije napravljeno, jer već od 31. 10. 1819. g. br. 23511 nadopunjeno traženje postavljanja veterinara u svim njemačkim pokrajinama s plaćom od 600 forinti. Za ova mjesta dolazili su u obzir graduirani liječnici i diplomirani ranarnici koji su kao stipendisti ili asistenti stekli veterinarsku naobrazbu na Bečkom vojno veterinarskom institutu. Dvorska kancelarija izdaje Dekret o postavljenju zemaljskih veterinara u sjedištima zemaljskih vlada. Veterinarska služba bila je podvrgnuta sanitetu, jer je zemaljski veterinar bio podređen zemaljskoj vladi, a zemaljski protomedik neposredni mu je pretpostavljeni. 
U Bečkom veterinarskom zavodu bile su sljedeće kategorije učenika:

- obični kovači- u trajanju od godinu dana slušali su: teoriju o potkivanju, anatomiju, fiziologiju, nauku o lijekovima i specijalnu terapiju konja;

- poljodjelci- u trajanju od godinu dana slušali su: prirodopis, nauku o zdravstvu svih domaćih životinja i stočne zaraze;

- pastiri, lovci i ovčari- u trajanju od 2 mjeseca slušali nastavu iz sličnih predmeta kao i poljoprivrednici;

- časnici i konjušnici- u trajanju od godinu dana slušali su: prirodopis i dietetiku konja, teoriju potkivanja, anatomiju i fiziologiju konja, nauku o ergelama, eksterijer konja i sudsko veterinarstvo konja;

- budući okružni liječnici, okružni ranari koji su se inskribirali prvi kao slušači svoga studija u trećem, drugi $\mathrm{u}$ četvrtom godištu, samo nauka o zaraznim bolestima i veterinarsko redarstvo u trajanju od jednog semestra;

- pregled stoke i mesa- slušali su predavanja u trajanju od 3 mjeseca;

- kuršmitori-kuršmidi, konjski vidari ili vidari potkivači u trajanju od 3 godine, slušali su teoretsku i praktičnu nastavu iz: potkivanja kopita i papaka, anatomiju i fiziologiju konja, nauku o lijekovima, specijalnu patologiju i kirurgiju, nauku o operacijama, porodiljstvo, a pohađali su i klinike;

- pravi veterinari (magistri veterinarstva) slušali su nastavu u trajanju od 2 godine, a ovu titulu su mogli postići samo diplomirani liječnici i ranarnici. Polagali su dva stroga ispita pred komisijom, kojom je predsjedavao dekan medicinskog fakulteta i poslije svih položenih ispita dobivali su diplomu magistra veterinarstva.

Studij raznih oblika veterinarstva kod liječnika i kirurga održavao se na 4 načina:

- prvi su bili kraći tečajevi iz veterinarstva $u$ trajanju od pola do jedne godine koji su se održavali za liječnike i kirurge-ranare, koji su htjeli dobiti ovlaštenje za rad u javnoj zdravstvenoj službi (fizikat). Tečajevi su održavani na katedrama za veterinarstvo koje su negdje bile na medicini, drugdje na sveučilištima, a neke na veterinarskim školama i fakultetima. Prvi tečajevi počeli su 1775. g. u Beču, a nastava je bila iz zaraznih bolesti domaćih životinja.

- Drugo je bio redoviti studij „,veterinarstvo" za studente medicinskih fakulteta i za učenike mediko-kirurških škola. U Beču se ovaj predmet počeo slušati od 1819. g. pa sve do 1910. godine. Studenti medicine i kirurgije slušali su veterinarstvo u 5 . semestru, a đaci kirurške škole najprije u 3., a kasnije u 7. semestru (1823. g.).

- Treće je bio poslijediplomski studij odabranih liječnika i kirurga $u$ trajanju od 2 godine kada su dobivali naziv veterinar, a kasnije naziv magistar veterinarstva 1833.-1857. g. $\mathrm{Na}$ Veterinarskom institutu u Beču 1781. g. donesena je Uredba da svaki zemaljski fizik mora imati i naobrazbu iz veterinarstva. Ovakav oblik nastave uvest će se u Milanu (1791. g.), Würzburgu 1811. g., Berlinu 1820. g., u Gissenu 1842. g. Ovaj oblik studija završilo je 18 graničnih liječnika koji su službovali u regimentama Vojne Krajine, a među prvim studentima ovog studija je naš Marko Lukić.

- Četvrti je bio posebni oblik poslijediplomskog studija za medicinare $\mathbf{i}$ kirurge koji su se pripremali kasnije za predavače. Od njih su birani zemaljski veterinari i dobivali su naslov magistra veterinarstva.

Razvoj veterinarskog školstva u Beču

1. K. K. Pferde-curen und Operationsschule ili škola za operaciju i liječenje konja (1766.-1777. g.) koju Rapić naziva Niža vojno veterinarska škola u Beču, a u literaturi ima obično sinonim Scotti-eva veterinarska škola koji je bio njen direk- 
tor. Najprije se podučavalo liječenje konja, a kasnije je uvedeno i liječenje ostalih životinja, posebno goveda i ovaca. Kao poznati stručnjak iz konjogojstva i vrhovni inspektor konjogojstva boravio je kod nas u Slavoniji i Vojnoj Krajini kada ga je mijenjao Adami.

2. Od 1777.-1795. g. škola se zvala K. K. Thierspital što znači Veterinarska bolnica, a njen je direktor bio Wolstein koji je preuzeo predmet veterinarstvo na medicini zbog stalnih nesuglasica s Adamijem 1777./78. g. U carskoj Uredbi od 1785. g. vidi se da je veterinarstvo među osnovnim višim predmetima koji su medicinari slušali u 5., kasnije u 7. semestru, a učenici kirurške škole u 3. poslije u 5. semestru. Od 1785. g. u Beču veterinarska struka dobiva znanstveni stupanj. ${ }^{6}$.

3. Od 1795.-1808. g. škola se zvala K. K. Militâr-Thierarzneyschule i to je drugo povojničenje škole jer su trebali vojsci, a školovanje je trajalo 2 godine. Direktor je bio najprije prof. dr. Knobloch ${ }^{7}$, a iza njega prof. dr. Ignatz Josef Pessina 1807. godine.

4. Od 1808.-1812. škola se nazivala K. K Militar -Thierzneyschule institut kojeg vodi prof. Pesina, a iza njega prof. dr. Johan Ubald Fecher. Čini se da se naziv veterinar za završene studente dobiva 1803. g. Od 1808. g. veterinarstvo su mogli studirati liječnici i kirurzi kao poslijediplomski studij $\mathrm{u}$ trajanju od 2 godine. Iste godine, uveden je i specijalistički studij opet samo za završene liječnike i kirurge koji su bili plaćeni i nazivani su umirovljenicima. Poznato je da su 2 liječnika i 2 kirurga koji su za cijelo vrijeme studija dobivali plaću zbog čega se nazivaju stipendisti Oni su se kasnije birali za profesore na veterinarskim školama, medicinskom fakultetu i za šefove veterinarske službe.

6 Orban, R. (1976.): Studij veterinarstva za liječnike i kirurge $u$ bivšoj Habsburškoj monarhihji. Sekcija Hrv. Naučnog društva, 1976., str. 46.

7 Osnivač prvog veterinarskog časopisa $u$ Monarhiji "Sammlung der vorzüglichen Schriften aus der Thierarzney.
Ovaj studij najviše su upisivali niži i viši kirurzi. Stipendisti su ukinuti 1908. g.

5. K. K. Thierarzney-Institut an der Medizinisch.-kirurgischen Fakultât je Veterinarski institut u sklopu Sveučilišta od 1812.-1850. godine. Prof. dr. Fridrich Bernarsd Viet ${ }^{8}$ bio je njegov direktor koji je na medicini predavao sudsku medicinu i medicinsko redarstvo, a na veterini patologiju, internu i zarazne bolesti. Spajanjem Veterinarske škole s Medicinsko-kirurškim fakultetom Sveučilišta znatno je podignut rang veterinarskog učilišta koji se zvao institut, a koji je potpadao pod zamjenika direktora tog fakulteta. Od 1816. g. direktorom postaje J. Emanuel Veith, a 1821. g. Ivan Lidl. Kako je u školu dolazilo puno kandidata s nižom izobrazbom uprava je Instituta 1823. g. osnovala osnovnu školu veterinarske struke u koju su na jednogodišnji tečaj primani: potkivači, agronomi i ekonomi, oficiri, jahači i konjušari, pregledavači mesa i stoke, lovci, ovčarski majstori ${ }^{9}$. Veterinarski pomoćnici (kuršmidi) slušali su dvogodišnji tečaj i dobili naslov konjski liječnik. (Rossartz). U prvoj polovici 18. st. Vojna Krajina namješta liječnike-veterinare koji su ujedno i prvi školovani u veterinari u Hrvatskoj. U prvoj polovici 19. st. pojavljuju se $u$ Hrvatskoj i prvi županijski veterinari. Od 1849. g. studij veterine produžuje se na 3 godine, a uvjet za upis bila je niža gimnazija, a poslijediplomski studij za liječnika i kirurga i dalje je bio 2 godine, ali se od 1841. g. dobivali naziv magister medicinae veterinariae što je 1857 . godine ukinuto.

8 Po specijalnom nalogu cara 1815. g. pregledava karantene po istočnoj obali Jadrana od Venecije preko Pule Splita i Dubrovnika vrativši se iza inspekcije u Zadar koji je bio sjedište austrijske Dalmacije i tu je čekao odobrenje svog prijedloga novog zakona o primorskoj higijeni. Obolio je od tifusa i u Zadru je i umro.

9 Burić, M. (1984.): Veterinari u povijesti zdravstvene kulture Osijeka 19. stoljeća. Četvrti znanstveni Sabor Slavonije i Baranje Sv. 1. JAZV str. 687-696. 
6. K. K. Militâr-Thierarzney InstitutVojno-veterinarski institut od 1850.-1896. g. Veterinarsko školstvo dolazi pod upravu vojske i mnogi profesori smatraju da je to veliki udarac za veterinarstvo. To je treće povojčenje škole i djelo je generala Škorića (rođen u Mahičnu kod Karlovca) koji je bio osobni prijatelj cara Franje Josipa I. te je kao ministar vojske mogao to provesti s 22 godine. No, ipak za ovih 46 godina napravljene su neke pozitivne promjene tako je studij trajao za civile i vojne veterinare 3 godine, a za pomoćnike 2 godine. Od 1850. g. studij na K. K. Militar Thierarznei Institut zu Wien trajao je 3 godine ${ }^{10}$ koji će po jednom spisu iz 1863. g. nazivati "Živinovidarski zavod“, a veći broj podataka iz 1873. g. i kasnije naziva se „C. K. živinarski zavod“. Za upis u ovaj Zavod u Beču je 1850. g. trebala prednaobrazba od 3 razreda osnovne škole, 1871. g. šest razreda srednje škole, 1886. šest razreda gimnazije ili realne gimnazije. ${ }^{11} \mathrm{Od}$ 1853. g. poslijediplomski studij mogli su upisati i osobe koje nisu liječnici, to jest osobe sa samo završenom srednjom školom. Od 1857. g. navodi se da će se u buduće u veterinarskim školama, na veterinarskim institutima školovati samo jedna vrsta liječnika za životinje „Thierarzt" što se moglo objasniti da više nije bilo škole za kuršmide, tj. kovače. Predviđeno je da studij traje 3 godine, a upisati se mogao kandidat koji je imao od 17-24 godine i koji je završio najmanje nižu gimnaziju. Nigdje se još ne spominje stručni naziv veterinar, a veterinarstvo samo spominje $\mathrm{u}$ predmetima nastave sudskog veterinarstva i veterinarske policije. Od 1859. g. stipendisti su mogli biti samo doktori medicine, a kirurzi više nisu primani. Naputkom Državnog ministarstva i Ministarstva rata u Beču 1863. g. daje se dozvola

10 Benčević, Z. (1929.): Prilozi povijesti veterinarstva Hrvatske i Slavonije od godine 1800.-1850. te povijest veterinarstva i stočarstva bivše Vojne Krajine do njezina ukinuća. Doktorska disertacija, Veterinarski fakultet u Zagrebu.

11 Lukačević, J. (1982.): O veterinarima i njihovoj djelatnosti u Slavoniji u drugoj polovici 19. stoljeća. Vet. arhiv 52, 21-29. obavljanja veterinarske prakse konjskim vidarima u slučaju napuštanja vojske pod uvjetom da su novog sustava (absolutorij 1862.-1864. g.) s dužim boravkom u vojsci i da su dobro obavljali svoj posao. Od 1871. g. uvodi se trogodišnji studij, a dobiva se naziv ",adjunki“ neka vrsta docenta ili profesora. To su mogli biti samo liječnici ili oni veterinari koji su položili doktorat medicine. ${ }^{12,13}$ Godine 1874 . studenti II. godine studija slušaju predmet „Nauka o životinjskih pošastih i veterinarsko redarstvo".

7. Od 1897.-1905. g. postoje dvije ustanove Vojno veterinarski institut za vojne pitomce i Visoka veterinarska škola za studente (K. K. Militâr Thierarzney Institut i K. K. Tierarztliche Hochschule). Prvi put se $u$ nazivu škole spominje životinja. Za upis u obje škole uvjet je bio završena srednja škola s maturom, a studij je proširen na 4 godine od kada se rabi pojam veterinar, a ne više živinski liječnik. Naredbom od 30. 6. 1891. g. predviđaju se konjski vidari starog sustava (oni koji su do 1858. g. na Veterinarskom zavodu u Beču dobili otpusnicu, (apsolutorij) koji s obzirom na veterinarsku praksu imaju ista prava kao i diplomirani veterinari. U istoj Naredbi ni civilnim ni vojnim konjskim vidarima koji su prema svojoj svjedodžbi ovlašteni za potkivanje konja, kao i kovačima zabranjuje se vršiti veterinarsku praksu.

8. Od 1905.-1919. škola se zvala Visoka veterinarska škola i Vojna veterinarska akademija (K.u.k Tierartliche Hochschule, K.u.K. Militâr-Veternâr Akademie. Od 1908. g. uvodi se doktorat veterinarske medicine uz izradu disertacije i strogi ispit te je ukinut upis veterinarskih pomoćnika, a od 1912. g. uvodi se

12 Orban, R. (1977.): Studij veterinara kod liječnika i kirurga od 18 . do 20. stoljeća. Znanstveno društvo za povijest zdravstvene kulture, Zagreb.

13 Orban, R. (1995.): Katedre za veterinarstvo na medicinskim fakultetima i sveučilištima podunavskih zemljama $\mathrm{u}$ posljednja tri stoljeća. Vet. stn. 26, 35-38. 
akademski naziv veterinar (do sada bio stručni naziv). Od 1908. g. ukinuto je upisivanje veterinarskih pomoćnika, jer doktorat i kuršmid nisu mogli biti isto.

9. Visoka veterinarska škola od 1920.1976. (Tierarztliche Hochschule). Od 1927./28. studij je proširen na 9 semestara. Vojnih pitomaca više nema. Sveučilište za veterinarsku medicinu od 1976. godine pa do danas. ${ }^{14}$

Poznato je da je na K. K. Militar Thierarznei Institut zu Wien 1849. g. završio Matija Dužanić kao dvogodišnji tečaj što znači da je školovanje konjskih vidara tada trajalo 2 godine. Ovom diplomom osim što je dotični osposobljen za kovača i potkivača, stekao je i pravo na liječenje konja i pravo da bude sudski vještak kod pregleda konja.

Univerzitet u Innsbrucku osnovan je 1677. g., a od 1782.-1792. g. je licej.

14 Orban, R. (1976.): Razvoj izobrazbe veterinara na Veterinarskoj školi u Beču od 1765. g. (Rukopis).
Učitelji veterinarstva bili su: Claudius Scherer (1781.-1790.), Franz Niedermayer (1790.-1804.), Josef Braun (1806.-1810.), nema podatka (1810.-1818.), Josef Braun (1818.-1846.), Gustav Svoboda (1847.1849.), Ludvig Mayer (1849.-1862.), Wenzel Kopatschek (1863.-1869.), Franz Wilander (1869.-1900.).

Univerzitet u Grazu osnovan je 1585. g. Od 1781. g. do 1812. g. bio je samo licej, a ne univerzitet. Katedra za veterinarstvo osnovana je 1786. g. Profesori veterinarstva bili su: Anton Buck (1777.-1782.), Josef Winumer (1782. 1786.), Joachim Plappart von Fraueuberg (1786.-1823.), Ignac Werle (1823.-1824.), Josef Hörmann (1824.-1839.), Franz Hruschauer (1840.-1841.), Franz Frisch (1841.-1863.), Bartholomäus Dresoluing (1863.-1864.), Josef Tott von Koch (1864.1891.), Albert Schündler (1891.-1911.).

U Salzburgu je bilo medicinskokirurško učilište. Predavači u najranija vremena su bili: Leopold Graf (1833.1843.) i Ignaz Schumacher (1845.-1877.).

\section{Education of equine healers, veterinary assistants and veterinarians at the Faculty of Veterinary Medicine in Vienna and other cities in todays Austria}

Petar DŽAJA, DVM, PhD, Full Professor, Faculty of Veterinary Medicine University of Zagreb, Croatia; Sonja SINKOVIĆ, DVM, Croatian Veterinary Institute, Zagreb, Croatia; Magdalena PALIĆ, DVM, Faculty of Veterinary Medicine University of Zagreb, Croatia; Josip MIHALJ, DVM, Veterinary Practice Soljani, Croatia; Krešimir SEVERIN, DVM, PhD, Full Professor, Faculty of Veterinary Medicine University of Zagreb, Croatia

This paper presents the development of veterinary education with special regard to the current Faculty of Veterinary Medicine, University of Vienna, since the majority of our veterinarians graduated from faculties at universities in Vienna, Budapest, Prague, Lviv and in Italy. The study of different veterinary specialties attended by physicians and surgeons was performed in four different ways: short veterinary medicine courses, the regular study of veterinary medicine, postgraduate study of selected physicians and surgeons, and special postgraduate study for physicians and surgeons. At the Faculty of Veterinary Medicine in Vienna, there were following categories of candidates for: ordinary blacksmiths, farmers, shepherds hunters and sheep keepers, officers, future county physicians and county healers, workers for meat and livestock inspection, veterinary assistants and veterinarians. The turbulent history of development and transformation of the Faculty of Veterinary Medicine in Vienna is presented through several phases until 1976, as follows: 1766$1777,1777-1795,1795-1808,1808-1812,1812$ 1850, 1850-1896, 1897-1905, 1905-1919 and from 1912-1976 untill today.

Key words: education; equine healers; veterinary assistants; veterinarians 